\title{
ENTREVISTA COM JACQUES GUTWIRTH
}

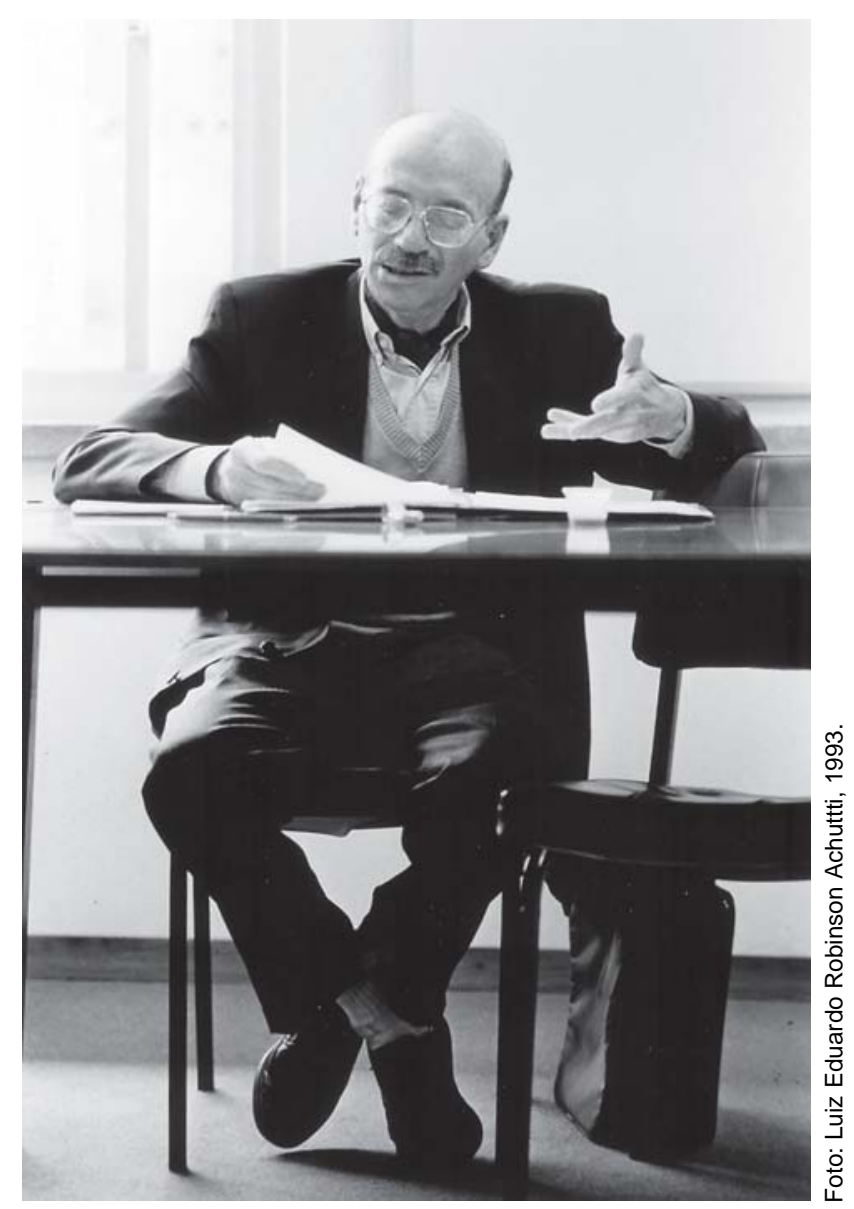

Esta entrevista com Jacques Gutwirth foi conduzida por Ari Pedro Oro, através de $e$-mails trocados com o entrevistado, e contou com a colaboração dos editores de Horizontes Antropológicos na formulação das perguntas. Aos 80 anos de idade, esse importante antropólogo francês ainda está ativo e fazendo projetos. Na entrevista ele fala de sua trajetória de vida e de sua carreira acadêmica, com destaque para os anos em que viveu no Brasil, em sua juven- 
tude, e dos laços afetivos e profissionais que estabeleceu com o país. Sua narrativa biográfica confunde-se, em grande medida, com a própria história da antropologia a partir da segunda metade do século XX e início do atual. Seu pioneirismo na criação da antropologia urbana na França e seus estudos na área da religião marcaram a antropologia contemporânea.

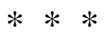

Ari Pedro Oro: Sua trajetória pessoal de vida, bem como de pesquisador, faz do senhor um cidadão do mundo, um homem da modernidade, um poliglota. Pode retraçar a sua história pessoal de vida?

Jacques Gutwirth: Com efeito, eu sou um pouco cidadão do mundo e poliglota e, em certa medida, um homem da modernidade. Para tanto, contam muito minha história pessoal e suas circunstâncias. Nasci em dezembro de 1926, filho de mãe holandesa e pai de origem polonesa, instalados em Anvers (Antuérpia), na Bélgica. Na minha primeira infância falei holandês, mas fui na escola na seção francesa e o francês foi e permaneceu minha primeira língua na escola e ao longo de toda a minha educação escolar e universitária. A Segunda Guerra Mundial começou em setembro de 1939, mas a Bélgica permaneceu neutra até a invasão alemã, em maio de 1940. Meus clarividentes pais, que conheciam a sorte dos judeus alemães nos campos de concentração, decidiram deixar a Europa. Em dezembro de 1939 meus pais, meu irmão e eu deixamos Anvers para o Rio de Janeiro, onde tivemos a chance de viver até maio de 1947. Aprendi rapidamente o português; após algumas semanas de permanência eu lia sem grandes dificuldades o Correio da Manhã, grande jornal da época. Em março de 1940, entrei no Liceu Franco-Brasileiro, em Laranjeiras, e obtive meu bacharelado francês em 1944. Quase no final da guerra conheci um livreiro italiano, um refugiado antifascista, que tinha sua loja na rua Bolívar, em Copacabana. Ele me iniciou no marxismo, o que me despertou o interesse pelos temas políticos, notadamente brasileiros. Acompanhei as peripécias do fim da ditadura de Getúlio Vargas, em 1945. Numa noite de futebol no estádio do Fluminense, por ocasião de uma brutal intervenção da polícia especial numa das arquibancadas, o público do setor de sócios revoltado cantou em coro a Marselhesa! Ao longo desse período assisti, também, uma reunião de Luis Carlos Prestes, que acabava de sair das prisões do Estado Novo, a ditadura então agonizante. 
Por ocasião de meu retorno a Antuérpia, em 1947, participei dos negócios com diamantes de meu pai. Graças a isto, aprendi o yiddish, língua franca entre os diamantários. Após o falecimento de meu pai, em 1957 fiquei doente e por ocasião de uma estada numa clínica em Davos, na Suíça - onde fortifiquei minha saúde, mas também minha prática da língua alemã - decidi abandonar os negócios, que decididamente não era o chá que eu gostava, embora eu não tivesse me saído assim tão mal naquela atividade. Eu queria fazer estudos superiores sem ter, porém, naquele momento, uma vocação precisa. Inscrevi-me, em 1958, na Universidade de Paris, e obtive um primeiro ano de licenciatura, denominada então de "propedêutica", sem abandonar meu domicílio de Anvers.

Em 1959, me instalei no Quartier Latin, em Paris, número 67 da rua SaintJacques, a 100 metros da Sorbonne, e comecei uma nova vida. Note-se que em maio de 1968, eu assisti da minha sacada vários enfrentamentos entre policiais e manifestantes. As noites eram bastante agitadas, felizmente intercaladas por uma trégua a cada dois dias, permitindo aos manifestantes e aos policiais tomarem um pouco de fôlego. No segundo ano de licenciatura obtive o certificado de "filologia portuguesa" e um outro de "estudos brasileiros". Com esses dois certificados tornei-me, de uma certa maneira, um semiprofessor de português! No ano seguinte, a partir da incitação do sociólogo urbano Henri Raymond, decidi fazer os cursos de sociologia e de etnologia.

Assisti, em novembro de 1960, no Museu do Homem, um primeiro curso de etnologia, ministrado por André Leroi-Gourhan (1911-1986). Este, que se designa muitas vezes como “unicamente” pré-histórico, era, no entanto, um notável etnólogo, autor de livros que permanecem hoje clássicos, muitas vezes reimpressos: L'Homme et la Matière (1943); Milieu et Techniques (1945); Le Geste et la Parole 1. Technique et Langage (1964), 2. La mémoire et les Rythmes (1965). André Leroi-Gourhan se expressava com uma voz muito baixa; não era um grande orador, mas eu fui totalmente seduzido pelo conteúdo de sua exposição, que colocava em realce todos os aspectos do homem, de seu pertencimento biológico às técnicas, à linguagem, à cultura e às relações sociais. Ele havia dito no início do curso que entre uma centena de participantes não mais do que quatro se tornariam etnólogos, sobretudo em razão da falta de perspectiva de carreira. Decidi, no fundo do meu íntimo, de estar entre os quatro eleitos! Solicitei uma entrevista com Leroi-Gourhan e o encontrei, pouco depois, no seu pequeno escritório no subsolo do Museu do Homem. Disse-lhe do meu interesse pela disciplina, sublinhando que eu já tinha 33 anos. Ele refutou imediatamente minha objeção: minha idade representava mesmo um trun- 
fo; em razão da minha experiência profissional, eu estava provavelmente mais maduro do que a maior parte dos estudantes mais jovens.

Após ter obtido uma licenciatura, fui admitido a me inscrever no Centro de Formação às Pesquisas Etnológicas (CFRE), dirigido por Leroi-Gourhan que chamávamos amigavelmente de "patrão" - e por Roger Bastide, que era o segundo titular de uma cátedra de etnologia na Universidade de Paris desde 1958. O CFRE preparava os futuros etnólogos na prática de campo. Além disso, eu havia proposto fazer uma tese de doutorado de 3 o ciclo em etnologia, ou sobre uma vila em Portugal - eu não conhecia esse país, mas tinha familiaridade com sua língua - ou sobre uma comunidade chassídica, judeus ultrareligiosos, em Anvers. Meu cunhado, que era originário desse meio, tinha, com suas saborosas anedotas, despertado o meu interesse por este tema. LeroiGourhan considerou que os chassidim, inseridos na modernidade urbana de Anvers, constituíam, de longe, o tema mais interessante e aceitou orientar minha tese. Portanto, em 1961 comecei minha pesquisa de observador participante nessa comunidade. Diante da extensão do meu trabalho, Leroi-Gourhan procedeu à sua transformação em tese de Doutorado de Estado, que defendi em junho de 1969, na famosa sala Louis Liard, na Sorbonne. O júri era composto por Bernard Blumenkranz (historiador do judaísmo), Roger Bastide, Jean Guiart (um renomado especialista na Oceania) e Leroi-Gourhan. Meu trabalho foi publicado pouco depois (Gutwirth, 1970).

Desde 1968 eu fora recrutado como pesquisador no CNRS. Trabalhei também um pouco sobre temas franceses, notadamente as associações de lazer em Chatillon-sur Seine, pequena cidade de Côte d'Or (Gutwirth, 1972a). Em 1971, fiz uma primeira incursão no continente americano, com uma pesquisa sobre os chassidim em Montreal (Gutwirth, 1972b, 1973a).

Interessei-me, também, sobre questões epistemológicas, em particular sobre a pertinência científica do método etnológico. Fazendo referência a Jean Piaget, psicólogo, epistemólogo, mas também defensor notável, e um pouco desconhecido, do “estruturalismo genético” (Piaget, 1968), eu defendia nossa disciplina:

[...] a pesquisa etnológica, desde seu início em campo, é particularmente fiel ao que é essencial da lógica operativa do sujeito no domínio do conhecimento, isto é, os processos de equilíbrio cognitivo por compensações ativas do sujeito [...]. No método etnológico, este conhecimento operativo se pratica efetivamente por aproximações equilibrantes, por um jogo de antecipação e de retroação (feedback) entre sujeito e objeto de pesquisa. (Gutwirth, 1973b, p. 775).

Horizontes Antropológicos, Porto Alegre, ano 13, n. 27, p. 313-331, jan./jun. 2007 
Num artigo publicado em português, na revista de vocês (Horizontes Antropológicos) (Gutwirth, 2001a), retomei esse tema ampliando-o à questão do desconstrutivismo excessivo vindo dos Estados Unidos, cuja moda parece hoje um pouco passada.

Em 1973 e em 1974, fui destacado por dois anos como professor na Universidade de Provence em Aix; depois, em 1975, obtive uma bolsa "pós-doc" da National Science Foundation, dos Estados Unidos, e do CNRS, para a permanência de um ano nos Estados Unidos. De novembro de 1975 até o ano de 1995, meu campo maior de pesquisa se situou nos Estados Unidos. Acrescento que meu inglês (à americana) foi muito beneficiado.

Por certo, eu continuava minhas pesquisas sobre o chassidismo e meu programa pós-doc comportava uma pesquisa sobre ele em Boston e em Nova Iorque, mas eu também queria fazer uma investigação sobre judeo-cristãos, ou “judeus messiânicos”. São judeus convertidos ao cristianismo evangélico, mas que mantém festas e liturgia judaicas. Eu não queria permanecer especialista somente do chassidismo; entrementes, já havia realizado uma pesquisa no meio protestante em Cévennes (Gutwirth, 1975, 1978a). Nos Estados Unidos eu me encontrava doravante confrontado a grupos religiosos bastante lábeis, situados no contexto de grandíssimas cidades e, para os judeo-cristãos, em Los Angeles, uma imensa megalópole "pós-urbana”. Interessava-me, portanto, pelos problemas metodológicos e epistemológicos que resultavam desse contexto bastante diferente dos encontrados pelos etnólogos “clássicos”. Daí meu interesse pela antropologia urbana que havia começado a sua forte expansão no fim dos anos 1960 nos Estados Unidos e, também, em outros lugares. Publiquei, então, meu primeiro artigo sobre pesquisa no meio urbano (Gutwirth 1978b), e organizei um colóquio sobre a antropologia urbana por ocasião de um grande congresso da Associação Francesa de Antropologia, em 1981, em Sèvres, perto de Paris. A partir das comunicações apresentadas ocorreu a publicação, em L'Homme (1982), de um número temático consagrado à antropologia urbana.

Em 1983, juntamente com minha amiga Colette Pétonnet, propus ao CNRS a criação de uma equipe de antropologia urbana, aceita inicialmente na forma experimental de uma “jovem equipe” e, em seguida, em 1988, como laboratório próprio do CNRS. Entrementes, continuei minhas pesquisas sobre os judeus messiânicos dos Estados Unidos, que culminaram com a publicação de um livro (Gutwirth, 1987). Foi também em 1985 que, instigado por Claudia Fonseca, aceitei com prazer assumir o programa de intercâmbio Capes-Cofecub entre a unidade de ensino de Ciências Sociais da Universidade Paris V - onde desde 1982 eu 
detinha um seminário de doutorado em Antropologia Urbana - e o Departamento de Antropologia da UFRGS, em Porto Alegre, a partir do qual realizei diversas estadas no Brasil e mesmo uma pesquisa de campo em companhia de Ari Pedro Oro (Gutwirth, 1991).

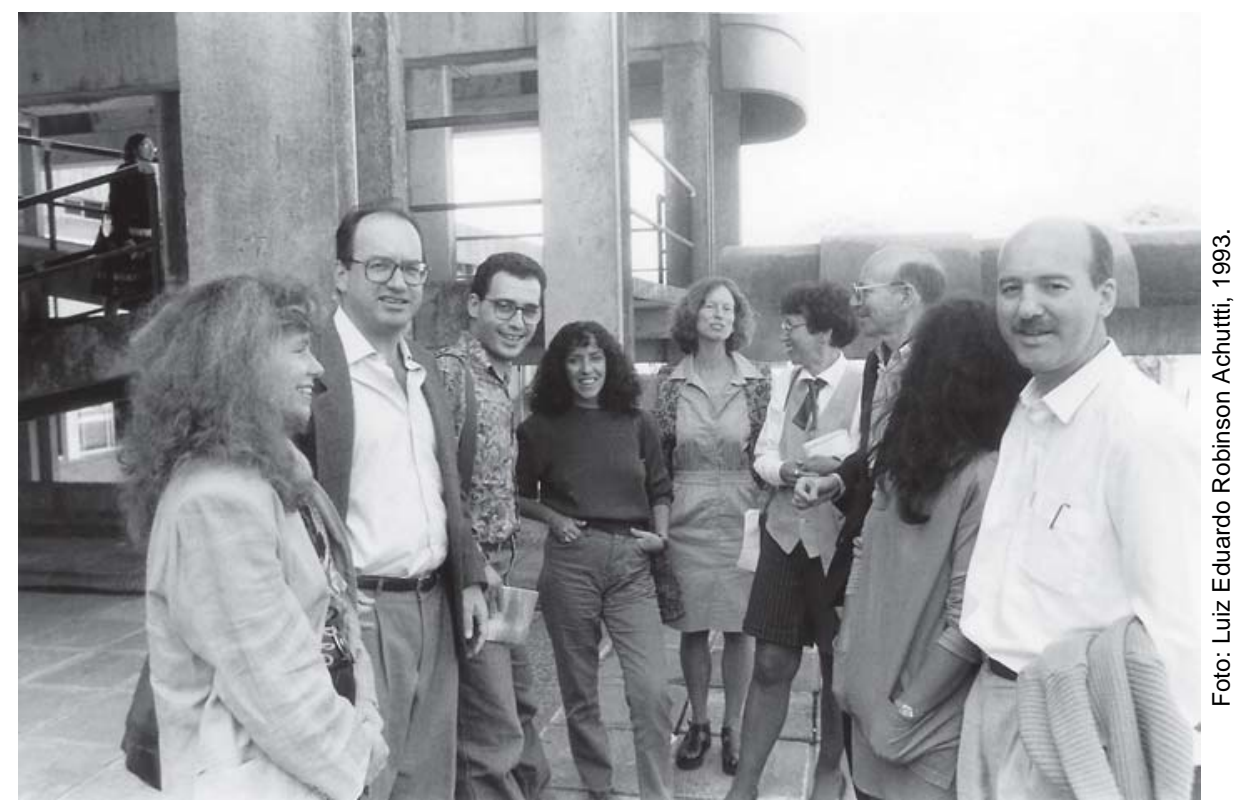

Da esquerda para a direita: Cornelia Eckert, Ruben George Oliven, Bernardo Lewgoy, Daisy Macedo de Barcellos, Claudia Lee Williams Fonseca, Maria Noemi Brito, Jacques Gutwirth, Ondina Fachel Leal e Ari Pedro Oro.

Os judeo-cristãos e os evangélicos que eu encontrava me falavam freqüentemente de programas de rádio e de televisão, apresentados por pregadores atuando na televisão, os "televangelistas". Dei-me conta que essa religião midiática fazia parte da cultura dos pesquisados que eu havia encontrado. Em 1985, ao término de minhas pesquisas sobre os judeus messiânicos, decidi realizar uma pesquisa sobre este fenômeno (voltarei sobre isso mais à frente), que culminou num livro (Gutwirth, 1998).

Em 1982, após o falecimento de Suzanne, minha primeira mulher, fiel companheira de minhas peregrinações na América do Norte, eu havia, em 1987, casado com Christa, uma alemã. A partir de 1994, resido permanentemente em Frankfurt, na Alemanha; ensinei no Institut für Historische Ethnologie da universidade da cidade, durante três semestres, em alemão - aprendi essa língua 
somente pela prática e leituras - mas os estudantes pareciam me compreender bem! Desde 1992 eu me encontrava, em princípio, aposentado. Doravante, enquanto “diretor de pesquisa honorário” do CNRS, meu único verdadeiro passatempo continuava a pesquisa! Continuei, portanto, meus trabalhos. Após meu livro sobre os televangelistas, voltei a me interessar pelos chassidim. Trabalhei com meus próprios materiais, mas, também, com os resultados de outros estudos e informações de diversas fontes (sobretudo da Internet) para um livro dedicado ao renascimento do chassidismo, principalmente em Anvers, nos Estados Unidos e em Israel. Em 1945, após o judeocídio nazista, havia no total aproximadamente 20 mil fiéis; hoje eles são provavelmente 400 mil no mundo! Isso culminou num livro (Gutwirth 2004, 2005a).

Sou um homem de campo, mas alguns desconfortos cardiovasculares e a idade chegando tornavam a pesquisa na forma da observação participante bastante pesada. Então, me interessei a certos episódios da história recente da etnologia, aos quais, de alguma forma, participei. Assim, pesquisei sobre a história e o papel do Centro de formação para a Pesquisa Etnológica, que cumpriu um papel considerável para a formação dos etnólogos na França, de 1946 a 1969 (Gutwirth, 2001b). Realizando este trabalho quis também fazer justiça a Leroi-Gourhan como etnólogo que havia criado essa entidade. Após, me interessei sobre o papel de Roger Bastide como professor de etnologia na Sorbonne, de 1958 a 1968 (Gutwirth, 2005b), e, enfim, recentemente escrevi uma contribuição sobre a história da antropologia urbana na França - texto que espero ver publicado brevemente.

Ari Pedro Oro: Que significado teve para o senhor ter passado parte de sua juventude no Brasil?

Jacques Gutwirth: Uma grande importância. Chegamos de navio no Rio em 29 de dezembro de 1939 e nos dirigimos ao hotel Central, destruído há muito tempo, na praia do Flamengo. Eu tinha 13 anos, mas após o desembarque a comoção foi forte. Naquela tarde fazia bastante calor, a luz era intensa, o barulho da avenida e da praia me atordoaram e chorei copiosamente no meu quarto do hotel. A adaptação foi para mim bastante lenta. Na época, o Rio era uma cidade relativamente tranqüila, mas os ritmos e as maneiras de ser eram bastante diferentes do que eu havia vivido até então. Com o tempo, porém, me habituei; eu e meus camaradas do Liceu Franco-brasileiro jogávamos futebol como os outros - os rachas - na praia de Copacabana. 
Enquanto na Europa a guerra fazia estragos e os judeus eram aniquilados, nós estávamos confortavelmente abrigados. Esta é, aliás, uma das razões que me fizeram aceitar de imediato a responsabilidade do programa de intercâmbio Paris V-UFRGS; eu tinha uma dívida moral em relação ao Brasil acolhedor, onde meu pai pôde trabalhar imediatamente e ganhar a sua vida. Depois veio meu interesse pela vida política, a cultura e a literatura brasileira. Eu ia regularmente à livraria da Civilização Brasileira, na rua do Ouvidor, no centro da cidade. Li Jorge Amado, Graciliano Ramos, José Lins do Rego, Gilberto Freire, Euclides da Cunha, etc. Eu tinha amigos brasileiros e por ocasião do meu retorno à Bélgica, em 1947, fiz chegar durante muitos anos jornais cariocas que, com dois meses de atraso, me mantinham a par do que ocorria lá; Internet e suas informações instantâneas estavam ainda muito distantes! Após a França - minha pátria de adoção a partir 1959 - o Brasil é o outro país ao qual eu me sinto muito vinculado e minhas estadas no quadro do programa de intercâmbio constituíram uma grande alegria para mim. Guardo muito boas amizades com os colegas de Porto Alegre.

Ari Pedro Oro: O senhor foi um dos fundadores da antropologia urbana na França. Que resistências, ou desafios, foram necessários serem superados para introduzir, na época, esse gênero novo de fazer antropologia?

Jacques Gutwirth: Entre 1961 e 1969, fui um dos primeiros etnólogos da França a realizar um trabalho numa grande cidade ocidental, em Anvers, na Bélgica (ver acima). Tive a chance de receber o apoio intelectual e moral necessário de Hélène Balfet, tecnóloga competente, que dirigia o Centro de Formação para a Pesquisa Etnológica (CFRE), e de André Leroi-Gourhan (ver acima).

Além disso, Roger Bastide, que, como vocês sabem, tinha lecionado por longos anos em São Paulo, de 1938 a 1954, era, desde 1958, titular de uma “cátedra de etnologia social e religiosa” na Universidade de Paris. Ora, ele havia realizado pesquisas sobre as religiões afro-brasileiras, notadamente o candomblé, sobretudo em Salvador da Bahia (Bastide, 1958). A etnologia na cidade era-lhe, portanto, familiar. Roger Bastide contava, entre os seus doutorandos no Museu do Homem, com Colette Pétonnet. Com o apoio de Bastide e de Leroi-Gourhan, ela empreendeu, em 1964, uma pesquisa na periferia parisiense e defendeu a sua tese de Doutorado de 3ํㅡㄹ Ciclo em 1967. Nesse trabalho, publicado em 1968, sob o título de Ces Gens Là (Pétonnet, 1968), ela estuda uma "cidade de trânsito", conjunto de grandes imóveis de uma aglo- 
meração de 50 mil habitantes perto de Paris. No prefácio do seu livro Roger Bastide escreveu: "é preciso felicitá-la [Colette] de ter aplicado a este sujeito os métodos da etnologia... a cidade de Halle [J. G.: nome fictício] revive diante de nós, com suas bisbilhotices nos corredores, seus dramas ou seus momentos de festa, os ritos secretos das caves e as aventuras dos jovens no 'mato' dos arredores. Porque a 'casa' aqui não é somente o apartamento; é, também, o corredor, a escada, as caves ou o pátio, cada subgrupo, grupo sexual ou grupo de idade tendo seu próprio domínio, que ele forja e que o forja” (Bastide, 1968, p. 7-8). Esse trabalho de etnologia de quase 40 anos atrás, era, portanto, totalmente precursor, e sua temática permanece - e como! - atual.

Com efeito, Colette e eu, apoiados pelos dois grandes "patrões”, havíamos realizado essas pesquisas na esteira da etnologia clássica. Como M. Jourdain, o gentil homem burguês de Molière, que fazia prosa sem sabê-lo, nós fazíamos antropologia urbana de maneira espontânea.

No meu caso, o trabalho tinha por objeto uma comunidade de 400 pessoas, descrita e analisada no seu contexto mais amplo, notadamente o conjunto dos judeus de Anvers, 15 mil pessoas. Este estudo era inovador em certos aspectos: eu havia realizado uma investigação em minha cidade natal, numa comunidade, é certo, ultratraditionalista, mas de criação bastante recente, porque constituída de imigrados recentes fugidos da Shoah, cujas atividades econômicas, principalmente com diamantes, me eram familiares. Isso não pareceu muito estranho nas instâncias do Comitê Nacional do CNRS. Antes de defender minha tese, em 1969, fui nomeado, em outubro de 1968, pesquisador do CNRS. Pessoalmente, não lamento de ter tido dificuldades. Os etnólogos clássicos - africanistas e outros - encontravam em minha tese, ao menos nas grandes linhas, uma monografia bastante clássica. Para Colette, seus estudos sobre as cidades de trânsito, e mais tarde sobre as cidades da periferia, suscitaram por muito tempo menos compreensão de parte de nossos colegas, mas ela foi, mesmo assim, recrutada no CNRS, em 1969. É verdade que o apoio de Leroi-Gourhan e de Bastide fora importante, assim como, parece, o de uma notável especialista em pré-história, Annette Laming-Emperaire, que integrava, com os etnólogos, o Comitê Científico ad hoc, enquanto que o apoio de Leroi-Gourhan, mas também de Lévi-Strauss, havia jogado ao meu favor.

Entretanto, ao longo da primeira parte da década de 1970-80 tudo parece ainda imóvel: nenhum colóquio, na França nenhuma publicação coletiva se refere à etnologia ou à antropologia urbana. Enquanto isso, Colette Pétonnet e eu continuávamos nossas pesquisas e trabalhos no meio urbano, notadamente, no meu caso, em Montréal (ver acima). 
De outra parte, Gérard Althabe, um africanista discípulo de Georges Balandier, começa uma pesquisa nos HLM (imóveis de locação a preço “moderado"). Numa entrevista (Althabe, 1977), ele trata da antropologia nesse novo contexto. Afirma que será cada vez mais difícil praticar a etnologia no Terceiro Mundo. Os etnólogos, entre os quais ele próprio, efetuam, portanto, um retorno "ao hexágono".

Seria fastidioso evocar aqui os trabalhos dos diversos pesquisadores que, pouco a pouco, se ocupam da antropologia urbana. Citamos Marc Abelès, Yves Delaporte, Michel Bozon, Gerard Toffin. Entretanto, o verdadeiro progresso da nova subdisciplina data dos anos 1980. Encontros em que se trata da antropologia urbana se multiplicam. Assim, de 19 a 21 de novembro de 1981, em Sèvres, perto de Paris, a Associação Francesa de Antropologia (AFA), fundada em 1979, organiza um colóquio internacional intitulado “A Prática da Antropologia Hoje”. De minha parte, organizei ali o ateliê "Estudo das Sociedades Urbanas e Industriais”. Graças ao apoio do CNRS, pude trazer para este ateliê dois convidados estrangeiros: Ulf Hannerz, professor na universidade de Estocolmo, do qual eu havia lido com muita atenção um livro publicado em 1980 (Hannerz 1980), traduzido para o francês a partir de minha recomendação (Hannerz 1983), bem como Jack Rollwagen, fundador, em 1972, nos Estados Unidos, da revista Urban Anthropology. O colóquio, no seu conjunto, obteve importante repercussão. O jornal Le Monde, de 26 de novembro de 1981, consagrou uma página inteira a ele. Um artigo, intitulado “o futuro de um metiê singular”, assinala que para a etnologia houve notadamente uma superação das: “[...] 'prudências' e 'pudores’ que deixavam na sombra - o ar político de então contribuindo - sujeitos pouco 'nobres', dando doravante chances a domínios ainda não ou insuficientemente explorados: a antropologia urbana [...] a do trabalho e de suas representações” (Kajman, 1981).

A maior parte das intervenções do ateliê “Antropologia Urbana” do colóquio foram publicadas no número temático de L’Homme, intitulado “Estudos de Antropologia Urbana” (1982). Pouco antes, em 1982, Ethnologie Française havia publicado um número temático dedicado à "História da Etnologia Urbana”. Assim, duas grandes revistas de etnologia da França entregavam a carta de nobreza à nova subdisciplina.

Como ja disse, em 1983, Colette Pétonnet e eu obtivemos do CNRS a criação de uma equipe experimental que tornou-se, em 1988, o Laboratório de Antropologia Urbana (LAU), “UPR”, unidade própria de pesquisa do CNRS, que cresceu consideravelmente desde então. No âmbito do LAU desenvolveu- 
se um projeto de guia pedagógico que, sem ser um manual, devia mostrar, através de exemplos de pesquisa, como os diversos autores tinham pesquisado, construído seu objeto de pesquisa e qual era a sua abordagem epistemológica (Gutwirth; Pétonnet, 1987). Nessa obra, várias contribuições dizem respeito a subúrbios e a zonas da periferia urbana. A dispersão no campo, muitas vezes bastante vasto, dos participantes de um ou outro grupo estudado, e, portanto, a questão da construção do objeto, são também abordados nesse livro.

Pode-se dizer que a antropologia urbana estava doravante reconhecida. Com a urbanização galopante no mundo inteiro, muitos etnólogos “clássicos” acompanharam "suas” populações nas cidades.

Ari Pedro Oro: O senhor dedicou parte importante de sua vida intelectual em pesquisar e analisar o judaísmo, em suas diferentes expressões. Quais foram as motivações para desenvolver essa linha de pesquisa?

Jacques Gutwirth: Quando descobri, a partir de 1961, os chassidim, que até então tinham sido, para mim, terra incógnita - embora eu topasse com eles diariamente nas ruas do bairro de diamantários de Anvers - tive a intuição que suas comunidades ultra-religiosas nessa cidade me dariam as chaves para compreender a persistência bimilenar do povo judeu no que se chama Diáspora ou Dispersão. De fato, os chassidim que estudei na época viviam uma existência religiosa, social, cultural, e, também, um certo tipo de prática econômica artesãos-clivadores e metiês ligados ao capitalismo comercial (sobretudo corretores de lotes de diamante) - mas não estou seguro que minhas pesquisas trazem respostas acerca da persistência do judaísmo há dois mil anos, forjada certamente sobre fundamentos bastante análogos, como constataram muitos especialistas, notadamente Max Weber (1970), Werner Sombart (1911), Abraham Léon (1968) e Walter Zenner (1980). Seja como for, creio ter apresentado uma pesquisa aprofundada sobre uma comunidade chassídica específica que levava em conta sua vida religiosa, seu aspecto distintivo em suas nuanças - vestimentas, barba, papelotes, etc., suas atividades econômicas, suas relações de parentesco, etc. Mostrei, também, que seu modo de vida e sua religiosidade, malgrado especificidades próprias do chassidismo, era herdeira das tradições religiosas e de uma vida sociocultural pluriseculares, assegurando no plano histórico, mas também no presente, um máximo de identidade judia, enquanto que em outros setores da judaicidade, a assimilação e a identificação judia estão hoje, pelo menos borradas. 
Contestaram-me de não abordar suficientemente a vida mística e espiritual dos hassidim. Vários especialistas (Scholem, Buber e alguns outros) o fizeram, mas poucos deles evidenciaram sua vida quotidiana, nuanças e contradições nas comunidades, etc., o que fiz. Enfim, num trabalho recente, mais geral (Gutwirth, 2004, 2005a), mostrei como o movimento chassídico se desenvolveu nos últimos 60 anos, graças a diversos fatores, entre os quais sua presença nas sociedades democráticas, condições econômicas favoráveis e, também, uma benevolência de instituições e meios judaicos, que compreenderam que o chassidismo, notadamente alguns dos seus setores, contribuíram para a manutenção da identidade judaica, objetivo preconizado por essas instituições e meios.

Ari Pedro Oro: Outro objeto de suas pesquisas nos Estados Unidos foram os televangelistas, sobre os quais o senhor lançou um livro em 1998. Como procedeu metodologicamente para obter tal densidade etnográfica, observada nesse belo livro?

Jacques Gutwirth: Etnólogo praticando a observação participante e entrevistas informais, penso que esse tema guarda fidelidade a essas práticas; mas a etnologia é também a bricolagem dos meios, em função das possibilidades de pesquisa e das fontes disponíveis para atingir os fatos, a fim de dar boas descrições e análises pertinentes, tanto quanto possíveis. Com o televangelismo eu não desviava, aliás, de um tema maior da etnologia, o estudo dos fatos religiosos. É certo que, nesse caso, o contato entre os principais protagonistas e o público ocorria, sobretudo, pela mediação de uma tela de televisão, a interação dos telespectadores em direção dos televangelistas sendo, nesse momento, largamente tributário do telefone. Mas como pesquisar etnologicamente sobre um tema tão vasto? Nesse caso, a observação participante era realizada de forma diversa. De um lado, tratava-se de participar das reuniões animadas pelos predicadores; assim, eu havia acompanhado uma campanha de encontros de Billy Graham em Paris, em 1986, e estive em cultos dominicais, fundamento de suas emissões televisivas de Robert Schuller na sua "Crystal Cathedral", um monumento arquitetônico modernista realizado pelo conhecido arquiteto Philip Johnson, em Garden Grove, a cerca de 50 quilômetros de Los Angeles. Passei também algum tempo em Bâton Rouge (Louisiana), com Jimmy Swaggart, onde, num vasto domínio que comportava uma "universidade”, ocorriam suas reuniões, base de seus programas televisivos, ou, ainda, no campus de Christian Broadcasting Network, junto a Pat Robertson, em Virginia Beach, na Virginia, e, também, junto 
a alguns outros televangelistas menos conhecidos, como Paul Crouch, que dirigia sua rede de televisão religiosa, TBN (Trinity Broadcasting Network) situada então em Santa Ana, no Sul da Califórnia. Além disso, eu me ocupava, mais ou menos longamente, com as pessoas do público e, em certas ocasiões, com os colaboradores próximos dos predicadores. Eu era, é verdade, um observador direto, mas, também, diante de um aparelho de televisão, observando os programas dos televangelistas, e, por vezes, também junto a outros telespectadores.

Acercar-se e ouvir os televangelistas nos locais de gravações das emissões era bastante útil, porque eu os descobria também fora da câmera; e percebia, então, inúmeros detalhes reveladores. Além disso, pode-se conhecer suas concepções e detalhes relativos a suas vidas, graças a situações não retransmitidas em seus programas. As anedotas que eles contam, suas maneiras de se dirigir a seus colaboradores e ao público são, também, bastante reveladores de suas mentalidades e concepções. E, é claro, tem suas publicações, muitas delas cheias de detalhes autobiográficos. Há, obviamente, entre eles, diferenças confessionais (mesmo que todos sejam protestantes), embora os mais célebres, fora Schuller, sejam fundamentalistas. Há, também, nuanças em suas atitudes políticas, mas no conjunto eles estão mais próximos do Partido Republicano.

Pude também adquirir gravações de vídeo e áudio que permitiam rever programas já passados ou descobrir outros programas, entre eles alguns desaparecidos na época da pesquisa, notadamente os de Jim Bakker, implicado numa vasta trapaça em relação ao seu público, que o conduziu à prisão. Certos programas podiam ser vistos na França pelos satélites e hoje, graças à Internet, descobre-se sem dificuldade quando e em que canais esses programas são veiculados.

Enfim, havia, de parte de certos jornalistas e de outros observadores, boas descrições das atividades dos televangelistas mais célebres ou, ainda, do envolvimento de alguns deles com a justiça e o fisco. E, por fim, há as autobiografias e as biografias, “autorizadas” ou não, dos televangelistas, especialmente as de Billy Graham, Jerry Falwell e Robert Schuller.

Em todo o caso, minha "bricolagem”, que possuía o trunfo epistemológico de permitir recortes entre informações de fontes diversas, durou perto de dez anos e, de fato, creio ter recolhido materiais suficientes para dar uma certa densidade a meu livro.

De outro lado, num artigo bastante volumoso, para o qual dediquei perto de seis meses de trabalho, mostrei (Gutwirth, 1993) como certos televangelistas, particularmente Paul Crouch e, sobretudo, Pat Robertson, criaram ou adquiriram, a partir de suas emissões televisuais, estações de rádio e de televisão que, 
com o tempo, tornaram-se vastas empresas, negócios audiovisuais, que enriqueceram consideravelmente seus fundadores, principalmente Pat Robertson. Suspeita-se que a teologia e as perspectivas políticas desses televangelistas-homens de negócio sejam bastante influenciadas pelos seus interesses econômicos!

Em todo o caso, com o televangelismo eu me encontrava, em múltiplos níveis, no coração da modernidade mais marcante dos Estados Unidos, embora a hora da Internet, hoje largamente utilizada por varios pregadores, ainda não tivesse chegado.

Ari Pedro Oro: Mesmo aposentado, sabemos que mantém seu interesse pela pesquisa. Que projetos desenvolve nos dias atuais?

Jacques Gutwirth: Amo realizar pesquisas etnológicas de campo. Mas, a idade tendo chegado, a pesquisa participante torna-se uma tarefa bastante complexa, muito árdua; para uma conversa ou entrevista há múltiplos parâmetros que necessitam de uma grande concentração: ser diplomata, ouvir, gravar, de uma maneira ou outra, os dizeres do interlocutor, retrucar para colocar questões ou comentários que suscitam sua fala, prestar atenção às mímicas do observado. Nem falemos das longas horas passadas nos cultos religiosos, etc. De sorte que encontrei outros “campos” mais cômodos, de caráter histórico, campos onde fui eu mesmo ator participante. Assim, escrevi um artigo (Gutwirth, 2001b) sobre a história do Centro de Formação para as Pesquisas Etnológicas (CFRE), criado por Leroi-Gourhan no Museu do Homem, onde fui estagiário, mas também monitor e professor. Mostrei que o CFRE, que durou 27 anos, de 1946 a 1969, contribuiu de maneira notável para a formação de uma grande parte dos melhores etnólogos da França da segunda metade do século XX. Quis também mostrar que Leroi-Gourhan, pouco apreciado por certos estruturalistas - mas Lévi Strauss havia declarado ter uma grande estima para ele (Lévi-Strauss, 1988) - foi um elemento dinâmico para o desenvolvimento da etnologia na França. Escrevi, igualmente, um artigo sobre Roger Bastide enquanto professor de etnologia em Paris, de sua nomeação à Sorbonne, em 1958, até a sua aposentadoria, em 1968 (Gutwirth, 2005b). Aqui também sou testemunha porque tive Bastide como professor em dois diplomas universitários, o de Etnologia e o de História das Religiões; enfim, estive ao seu lado no CFRE como aluno e como monitor. Tratava-se de mostrar, nas suas nuanças, o papel importante de Bastide para o dinamismo da etnologia na França. LeroiGourhan e ele haviam, durante esses dez anos, montado, conjuntamente, um 
registro de etnologia bastante completo e coerente. Digamos, para ser breve, da tecnologia à etnologia religiosa, o que contribuíra para uma forte expansão da disciplina durante esse período. Enfim, recentemente escrevi um artigo (ainda não publicado) sobre a história da antropologia urbana na França, de seus inícios em torno de 1960 até hoje. Ali mostro, notadamente, que a antropologia urbana francesa não resultou dos trabalhos da Escola de Chicago. Colette Pétonnet e eu mesmo simplesmente adaptamos os ensinamentos de nossos mestres Roger Bastide e André Leroi-Gourhan, e, como disse, com seus encorajamentos, a temas urbanos. Gérard Althabe, também ele um fundador da subdisciplina, em sua prática de pesquisa igualmente ignorou essa escola. Outra constatação: alguns consideraram que a antropologia urbana era somente uma etapa da antropologia “do próximo”, isto é, do mundo urbano ocidental (Abélès; Rogers, 1992). Entretanto, a antropologia urbana desenvolveu-se, primeiramente, no "distante", nos países que pertenciam então ao Terceiro Mundo, Índia, África, e também Brasil. Ver, sobre esse tema, por exemplo, os livros de Gutkind (1974) e Basham (1978), sem esquecer os trabalhos mais antigos do Rhodes Livingstone Institute, na Zâmbia (por exemplo, Epstein 1958). Mesmo na França, alguns trabalhos isolados realizados no meio urbano desde os anos 1950 (Balandier, 1955, 1985) foram efetuados principalmente na África. A antropologia urbana continua hoje alegremente a sua obra. Citemos somente um livro notável, mesmo que não se trate de uma obra de antropologia urbana propriamente dita: Les Néo-indiens. Une Religion du III ${ }^{\circ}$ Millénaire, de Jacques Galinier e Antoinette Molinié (2006), uma obra consagrada à nova religiosidade sincrética dos índios peruanos e mexicanos, essencialmente do meio urbano.

Além disso, a abertura recente do museu "Museu do Cais Branly", ou das “Arts Premiers" onde o interesse pelas obras de arte prima largamente o de um olhar etnológico, que abraça o conjunto dos elementos materiais, da mais simples colher às máscaras mais sofisticadas que constituem as culturas materiais das sociedades - incluídas as nossas - (um dia as caçarolas com pressão, as velhas máquinas de escrever e de calcular, os walkman, os iPod e muitos outros elementos figurarão, se já não é o caso, nos museus de “cultura e de civilização”), conduziu-me a uma reflexão sobre esse problema. Existe há, certamente, 30 anos, se não mais, um divórcio entre a temática etnológica dominante, influenciada pelo estruturalismo, consagrado ao parentesco, à simbólica, etc., e, de outra parte, uma magra atenção às técnicas, à vida material, à base da vida dos homens. Por isso, com a colaboração de Bernard Dupaigne, do Museu do Homem, organizo, em novembro de 2007, um ateliê mesa-redonda 
sobre "Museus de Etnologia e Prática da Etnologia”. Os debates desse ateliê deverão alimentar discussões sobre as instituições etnológicas, por ocasião “de sessões plenárias da etnologia e da antropologia” que acontecerão em Paris, algumas semanas mais tarde.

Ari Pedro Oro: Durante anos o senhor foi o coordenador francês do acordo Capes-Cofecub realizado entre o PPGAS/UFRGS e a Universidade Paris IV. Como analisa hoje essa experiência?

Jacques Gutwirth: De 1985 a 1992, foi uma experiência positiva em todos os sentidos, como já disse em Memória da Antropologia no Sul do Brasil (Gutwirth, 2006). Para mim, pessoalmente, ela me permitiu reatar maravilhosamente com minha segunda pátria, o Brasil, criar laços de amizade duráveis com os colegas do Departamento de Antropologia da UFRGS e seus familiares. Recordarei aqui somente uma outra constatação importante: essa cooperação foi intelectualmente a de iguais, e ela foi proveitosa tanto para os participantes franceses quanto brasileiros.

Traduzido do francês por Ari Pedro Oro.

\section{Referências}

ABÉLÈS, Martc; ROGERS, Suzanne (Dir.). Anthropologie du proche. L'Homme, v. 32, n. 121, p. 7-13, 1992.

ALTHABE, Gérard. Le quotidien en procès. (Entrevista). Dialectiques, n. 21, p. 67-77, 1977.

BALANDIER, Georges. Sociologie des Brazzavilles noires. Paris: Armand Colin, 1955.

BALANDIER, Georges. Sociologie des Brazzavilles noires. 2e éd. augmentée. Paris: Presse de la Fondation Nationale des Sciences Politiques, 1985.

BASHAM, Richard D. Urban Anthropology: the cross-cultural study of complex societies, Palo Alto: Mayfield, 1978. 
BASTIDE, Roger. Le Candomblé de Bahia, rite Nagô. Paris: Mouton, 1958. [Reeditado com o título de Le Candomblé de Bahia. Pref. de Fernando Henrique Cardoso; introd. de Jean Duvignaud; adresse de Jean Malaurie. Paris: Terre Humaine, 2000].

BASTIDE, Roger. Préface. In: PÉTONNET, Colette. Ces gens-là. Paris: Maspéro, 1968. p. 7-9.

EPSTEIN, A.L.; Politics in an Urban African community. Manchester, Manchester University Press, 1958.

GALINIER, Jacques; MOLINIÉ, Antoinette. Les néo-indiens: une religion du III ${ }^{\circ}$ millénaire. Paris: Odile Jacob, 2006.

GUTKIND, Peter C. W. Urban Anthropology: perspectives on 'Third World' urbanization and Urbanism. Assen: Van Gorcum, 1974.

GUTWIRTH, Jacques. Vie juive traditionnelle: Ethnologie d'une communauté hassidique. Préf. André Leroi-Gourhan. Paris: Minuit, 1970.

GUTWIRTH, Jacques. Les associations de loisirs d'une petite ville, Châtillonsur-Seine. Ethnologie Française, v. 2, n. 1-2, p. 141-180,1972a.

GUTWIRTH, Jacques. The Structure of a Hasidic Community in Montreal. The Jewish Journal of Sociology, v. 14, n. 1, p. 43-62, 1972b.

GUTWIRTH, Jacques. Hassidisme et judaïcité à Montréal. Recherches Sociographiques, Québec, v. 14, n. 3, p. 291-325, 1973a.

GUTWIRTH, Jacques. Pour la méthode ethnologique. In: LEROI-GOURHAN, André. L'Homme, hier et aujourd'hui: recueil d'études en hommage. Paris: Cujas, 1973b. p. 775-783.

GUTWIRTH, Jacques. Piétistes juifs et protestants, une analyse comparative. Archives de Sciences Sociales des Religions, v. 40, n. 1, p. 53-66, 1975.

GUTWIRTH, Jacques. Superstition, ancêtres et piétisme en Cévennes. Autrement, n. 15, p. 160-171, 1978a.

GUTWIRTH, Jacques. L'enquête en ethnologie urbaine. Hérodote, n. 9, p. 38$55,1978 b$.

GUTWIRTH, Jacques. Les Judéo-chrétiens d'aujourd'hui. Paris: Cerf, 1987. 
GUTWIRTH, Jacques. Pentecôtisme national et audio-visuel à Porto Alegre (Brésil). Archives de Sciences Sociales des Religions, n. 73, p. 99-114, 1991.

GUTWIRTH, Jacques. Religion télévisée et business audio-visuel. Archives de Sciences Sociales des Religions, n. 83, p. 67-89, 1993.

GUTWIRTH, Jacques. L'Église électronique: la saga des télévangélistes. Paris: Bayard, 1998.

GUTWIRTH, Jacques. A Etnologia, ciência ou literatura? Horizontes Antropológicos, ano 7, n. 16, p. 223-239, dez. 2001a.

GUTWIRTH, Jacques. La professionnalisation d'une discipline: le centre de formation aux recherches ethnologiques. Gradhiva, n. 29, p. 25-41, $2001 \mathrm{~b}$.

GUTWIRTH, Jacques. La renaissance du hassidisme de 1945 à nos jours. Paris: Odile Jacob, 2004.

GUTWIRTH, Jacques. The rebirth of Hasidism. London: Free Association Books, 2005a.

GUTWIRTH, Jacques. Roger Bastide, l'enseignement de l'ethnologie et la formation à la recherche. Bastidiana, n. 51-52, p. 59-72, juil./déc. 2005b.

GUTWIRTH, Jacques. Uma bela experiência intelectual e humana: a cooperacão Capes-Cofecub 1985-1993, Porto Alegre-Paris. In: SANTOS, Silvio Coelho dos (Org.). Memória da antropologia no Sul do Brasil. São Leonardo: Editora da UFSC: ABA, 2006. p. 174-177.

GUTWIRTH Jacques; PÉTONNET, Colette (Ed.). Chemins de la ville: enquêtes thnologiques. Paris: C.T.H.S., 1987.(Le Regard de l’Ethnologue).

HANNERZ, Ulf. Exploring the city: inquiries toward an urban Anthropology. New York: Columbia University Press, 1980.

HANNERZ, Ulf. Explorer la ville: eléments d'anthropologie urbaine. Trad. Isaac Joseph. Paris: Ed.de Minuit, 1983.

KAJMAN, Michel. L’avenir d'un métier singulier. Le Monde, Paris, p. 2, 28 nov. 1981.

LÉON, Abraham. La conception matérialiste de la question juive. Paris: EDI, 1968. 
LEROI-GOURHAN, André. L'Homme et la matière. Paris: Albin Michel, 1943. LEROI-GOURHAN, André. Milieu et techniques. Paris: Albin Michel, 1945. LEROI-GOURHAN, André. Le geste et la parole 1: technique et langage. Paris: Albin Michel, 1964.

LEROI-GOURHAN, André. Le geste et la parole 2: la mémoire et les rythmes. Paris: Albin Michel, 1965.

LEVI-STRAUSS, Claude....nous avons lui et moi essayé à peu près de faire la même chose. In: ANDRÉ Leroi-Gourhan ou les voies de l'homme. Paris: Albin Michel. p. 201-206, 1988.

PÉTONNET, Colette. Ces gens-là. Paris: Maspéro, 1968.

PIAGET, Jean. Le structuralisme. Paris: PUF, 1968. (Que sais-je ?).

SOMBART, Werner. Die Juden und das Wirtschaftsleben. Leipzig: Dunker und Humblot, 1911.

TEIXEIRA, Sérgio Alves. A antropologia no Rio Grande do Sul. In: SANTOS, Silvio Coelho dos (Org.). Memória da antropologia no Sul do Brasil. São Leonardo: Editora da UFSC: ABA, 2006.

WEBER, Max. Le judaïsme antique. Paris: Plon; 1970.

ZENNER, Walter. American Jewry in the Light of Middlemen Minorities Theories. Contemporary Jewry, v. 5, n. 1, p. 11-30, 1980. 